\title{
Article \\ Finite Element Analysis of Proposed Self-Locking Joint for Modular Steel Structures
}

\author{
Gohar Nadeem, Nor Azizi Safiee *, Nabilah Abu Bakar, Izian Abd Karim and Noor Azline Mohd Nasir (D) \\ Department of Civil Engineering, University Putra Malaysia, Seri Kembangan 43400, Malaysia; \\ gs52862@student.upm.edu.my (G.N.); nabilah@upm.edu.my (N.A.B.); izian_abd@upm.edu.my (I.A.K.); \\ nazline@upm.edu.my (N.A.M.N.) \\ * Correspondence: norazizi@upm.edu.my
}

Citation: Nadeem, G.; Safiee, N.A.; Abu Bakar, N.; Abd Karim, I.; Mohd Nasir, N.A. Finite Element Analysis of Proposed Self-Locking Joint for Modular Steel Structures. Appl. Sci. 2021, 11, 9277. https://doi.org/ 10.3390/app11199277

Academic Editor: Kang Su Kim

Received: 9 September 2021

Accepted: 29 September 2021

Published: 6 October 2021

Publisher's Note: MDPI stays neutral with regard to jurisdictional claims in published maps and institutional affiliations.

Copyright: (c) 2021 by the authors. Licensee MDPI, Basel, Switzerland. This article is an open access article distributed under the terms and conditions of the Creative Commons Attribution (CC BY) license (https:/ / creativecommons.org/licenses/by/ $4.0 /)$.

\begin{abstract}
The intermodular connection between modules plays a vital role in the overall performance of modular structures. The separation between a column and connection is possible due to the absence of links (welding or bolting) since limited space is available between modules. This study proposed a self-locking joint to be used in a modular steel structure, connecting columns with a connection without need of extra space between modules. The behavior of the proposed connection subjected to monotonic load was evaluated using a finite element approach using ABAQUS software. The influencing factors contributed to the behavior of the self-locking connection and columns observed using a parametric study. The parametric study was conducted by varying beam thickness, bolt pretension force and friction coefficient $\mu$. Results indicate that the proposed connection can be classified as a semirigid connection according to Eurocode 3 and special moment frame (SMF) as recommended by AISC.
\end{abstract}

Keywords: modular steel structure; intermodular connection; spring pin; self-locking; finite element analysis

\section{Introduction}

Modular steel buildings (MSB) are a type of building that are constructed by placing and connecting prefabricated modules; this type of construction is comparatively new and has been adopted by many developed countries [1]. Silent features of this new construction mode include minimum onsite construction activity, while off-site fabrication is conducted in a manufacturing facility. A module, after building all basic facilities such as electric wiring, piping, painting, and cladding at the workshop, is transported to the construction site and brought together in the building. Modular steel construction (MSC) has gained attention by many countries due to its rapid construction techniques, sustainability benefits, higher precision of erection, better quality, and the possibility of removing and reusing modules. Due to these benefits, MSC model has been adopted to construct different types of multi-story buildings such as hostels, residential buildings, and offices.

The intermodular connections between modules plays an important role in the overall performance of a structure. Unlike conventional steel construction, workplace or space between modules is limited and onsite welding and bolting techniques to join beams and columns or modules are difficult to perform compared to conventional steel structures construction. Due to a lack of guidelines and code of practice, the design of modular structures has been subject to investigation by many researchers [2-16]. In recent years, a number of intermodular connections has been proposed, and their seismic performance under monotonic and cyclic loading has been evaluated experimentally and analytically [17-24]. Lawson proposed a single bolt joint to connect an upper and lower square hollow section (SHS) and angle section column of modules [25], as shown in Figure 1a. Deng et al. established a bolted welded connection to join four modules; the cruciform bolted module to module connection was reinforced by a welded cover plate [17], shown in Figure 1b. 
Annan conducted seismic analysis and experimental work on the proposed welded connection [16,26] plugin connection. Work [22] presented a plug-in connection, shown in Figure 1c for SHS columns; beams were connected by long-stay bolt where the column was not tied with components of a plugin connection $[19,22]$. Khan et al. proposed a novel connection where beams were connected by a long stay bolt and columns were connected with a connection by means of a bolted column tenon [27]. The issue associated with these connections is the requirement of a working space between modules, especially when four or eight modules are required to connect; this problem may limit the construction plan.

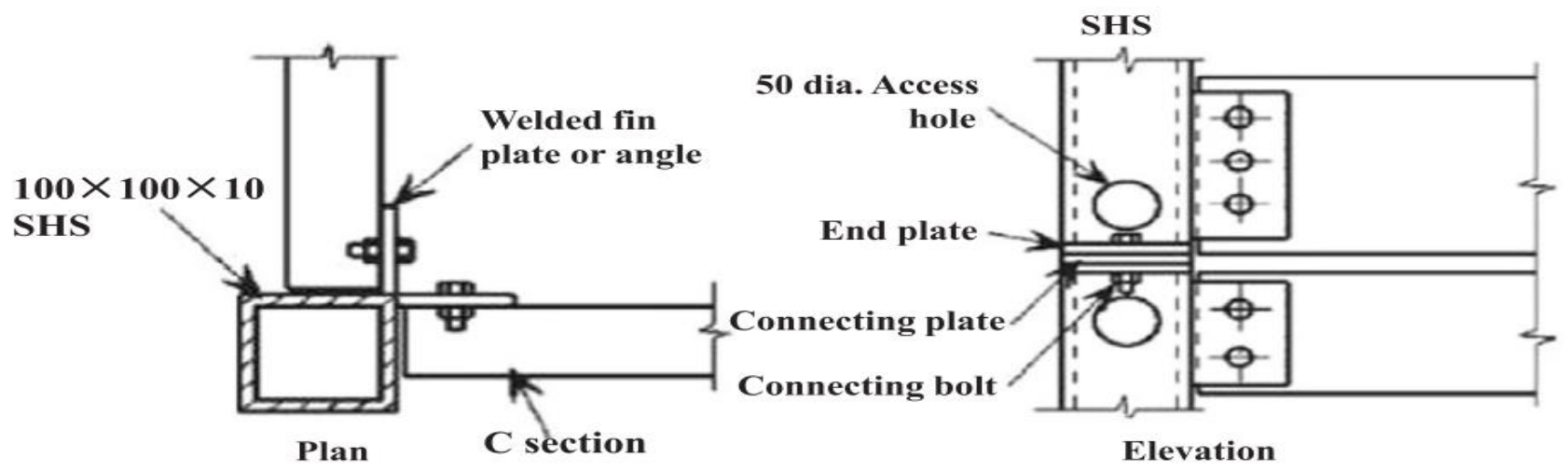

(a)

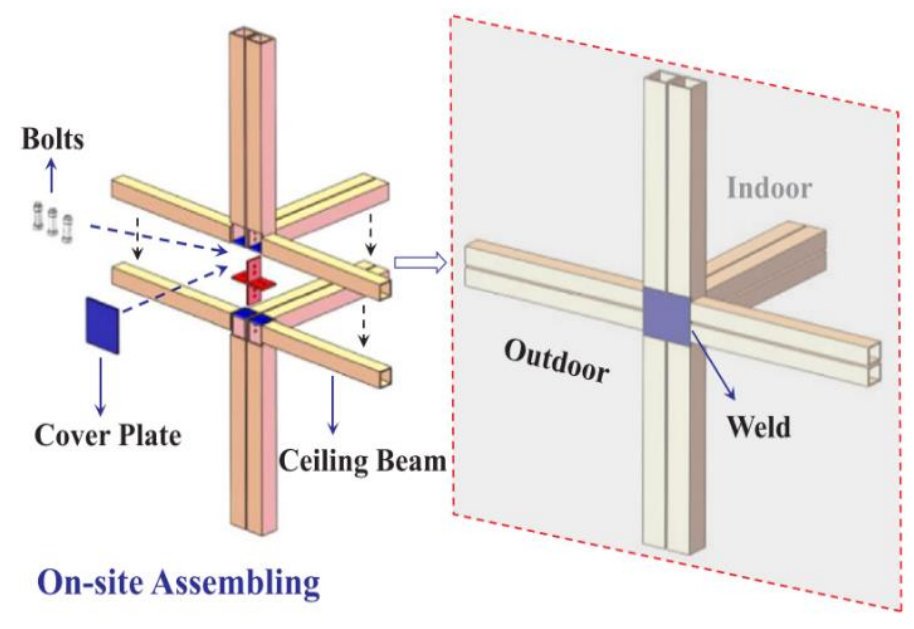

(b)

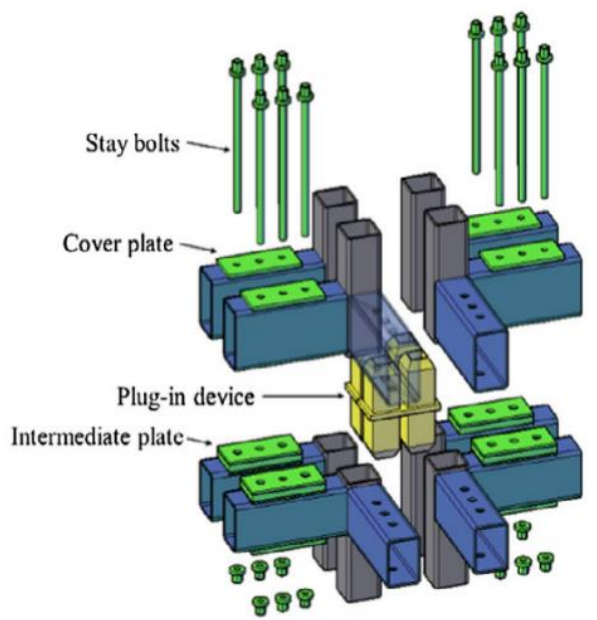

(c)

Figure 1. (a) Corner post using SHS or special sections attachments [25]. (b) Cruciform bolted module-to-module connection [17]. (c) Vertical welded connection [16].

This study proposed a self-locking joint to address the issues mentioned above of intermodular connections. The proposed connection uses a simple mechanism and does not require extra workspace between modules. It is suitable for corner, internal and interior joints as shown in Figure 2a. 


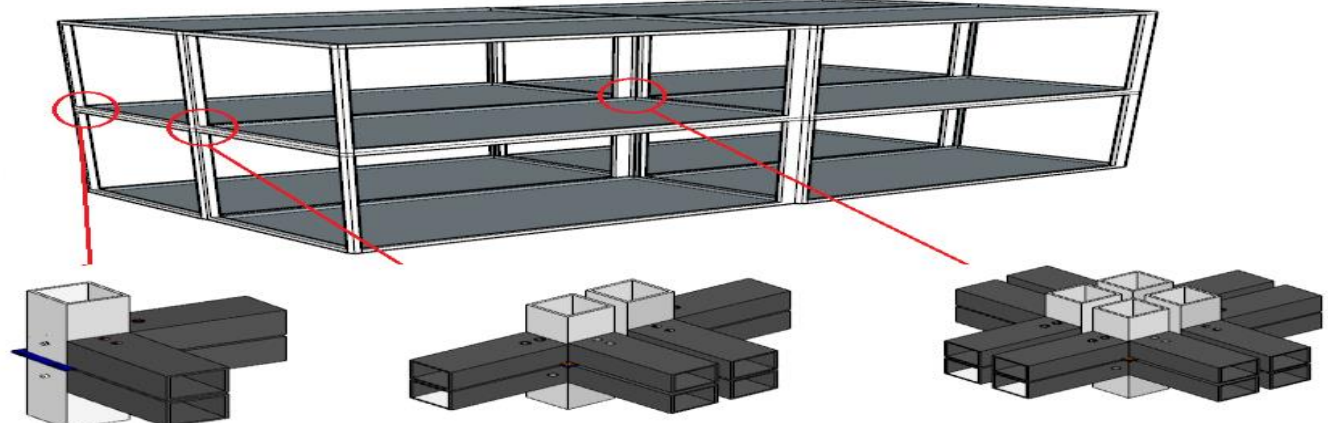

(a)
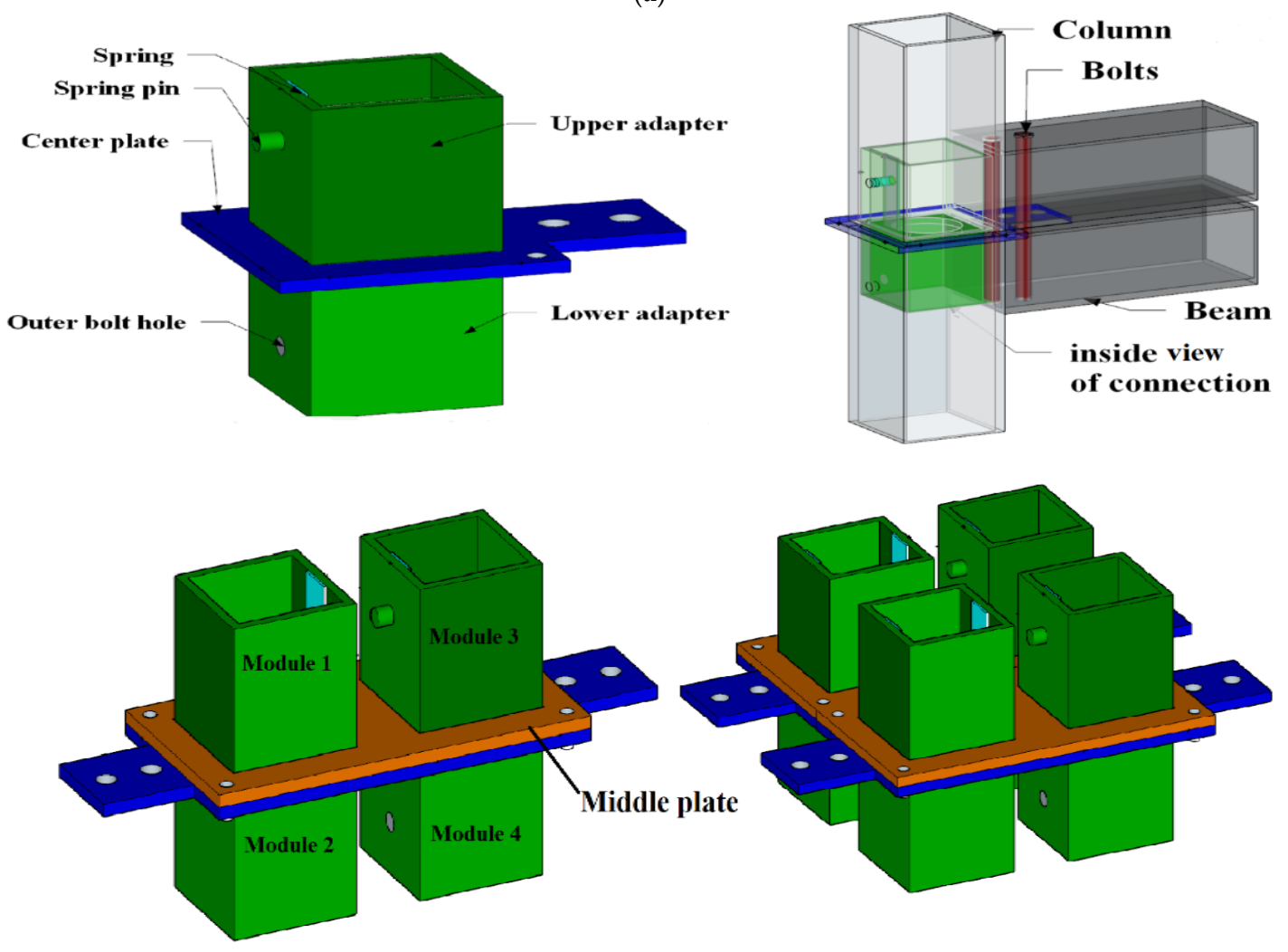

(b)
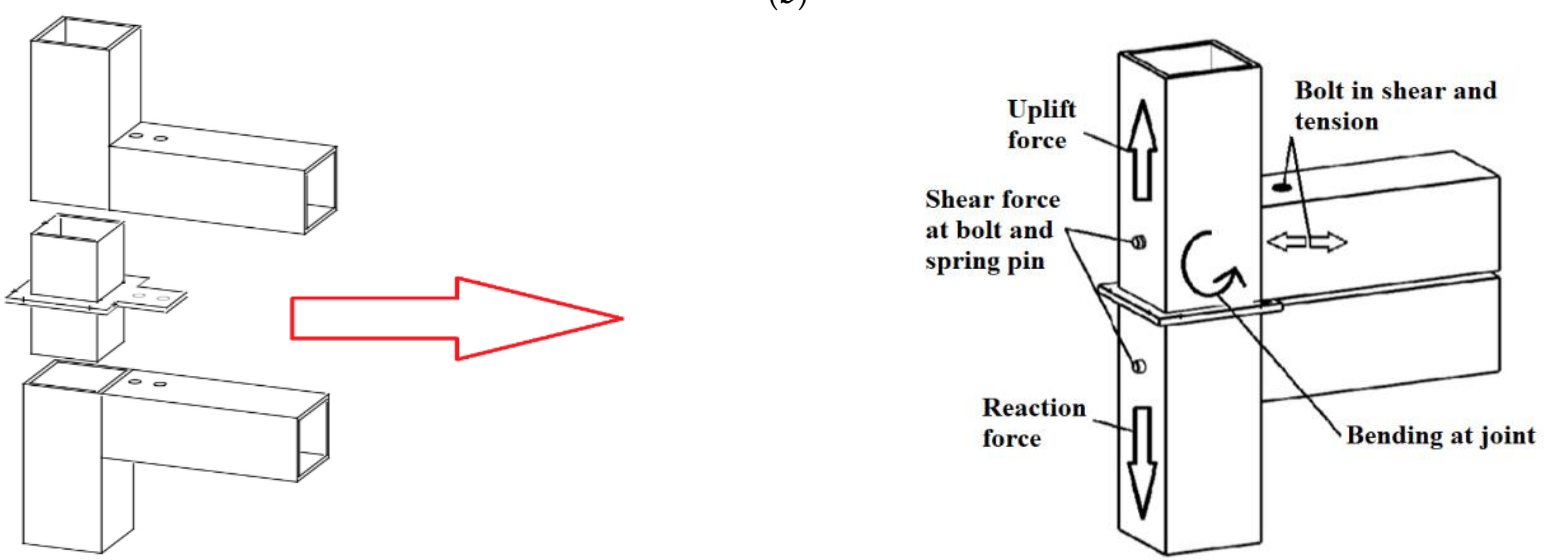

(c)

Figure 2. Details of proposed connection: (a) corner, internal and interior connection in MSB; (b) component details of proposed connection; (c) connection assembly forces at joint, reproduced from Khan et al. [27]. 
Due to its unique design, it is important to investigate the local and global behavior of this proposed connection. The behavior of this connection is simulated using a 3D finite element analysis using ABAQUS software [28]. Before simulating the behavior of the proposed connection, the modeling techniques were validated using experimental results obtained from Dai et al. [18]. A parametric study was then conducted to evaluate the effect of influencing parameters on moment carrying capacities, strength, stiffness, and mode of failure of joints. Discussion of results of parametric studies and numerical analysis helped to understand the behavior and working mechanism of the proposed connection.

\section{Working Mechanism of Proposed Intermodular Connection}

The proposed connection consists of upper and lower adapters, a center plate, middle plate, flat spring and a spring pin. Figure 2 shows the details of the proposed intermodular connection (IMC), this connection can be used to connect two, four, and eight modules without any in situ welding and requirement of the extra workspace between modules as shown in Figure 2a. As can be seen in Figure 2b, adapters are welded on both sides of the center plate, the flat spring is fixed inside the adapter by the means of welding at one end and is free at the other end. To connect adjacent modules in internal and external joints, a middle plate is used as in Figure $2 b$. This plate is laid on center plates, and the upper adaptor is passed through the square space provided on the middle plate. At each corner of the middle plate, dowel pins are provided for the alignment position of the connected modules. The gap between the floor beam and ceiling beam is the same as the thickness of the middle plate and center plate. All structural member materials and components of connection are composed of structural steel, except for the spring, which is composed of spring material (music wire).

Fixing this connection is easy and instant, with an adapter on each side of the center plate inserted into their respective columns (upper and lower columns). The upper column would tie with the adapter by means of an outer bolt at the outer face, while the lower column would be attached to the adapter by a self-locking mechanism of a spring; an inside push at the spring pin would be required to insert the adapter into the column; when the spring pin reaches its designated hole in the column, it becomes secured by spring action. The bolt would be tightened by a nut, whereas the spring would exert a constant force on the spring pin to remain in its position. This connection is designed to transfer horizontal and vertical loads and bending moments from one module to an adjacent module. Vertical forces can be transferred from the upper column to the lower column through the center plate between both columns. The floor and ceiling beams would be connected vertically by long bolts that hold both the beams together. Due to moments at the joints, an uplift force or normal force will be expected to be produced at the connection's outer face, as shown in Figure 2c, which may cause separation between the connection and the columns (in the absence of a link between columns and adaptor). The presence of a bolt and a spring will provide additional shear resistance to minimize the potential separation between columns.

\section{Finite Element (FE) Model}

The accuracy of finite element modeling is important for simulation-based studies. Therefore, before the finite element analysis of the proposed connection is carried out, the validation process of the modeling technique is conducted. For this purpose, the experimental modular connection specimen and result from [18] as shown in Figure 3a is used. 


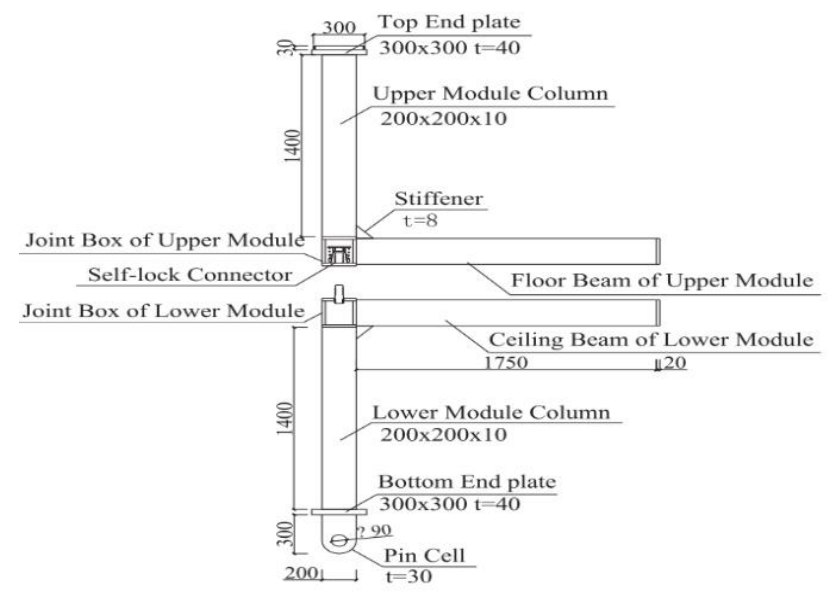

(a)

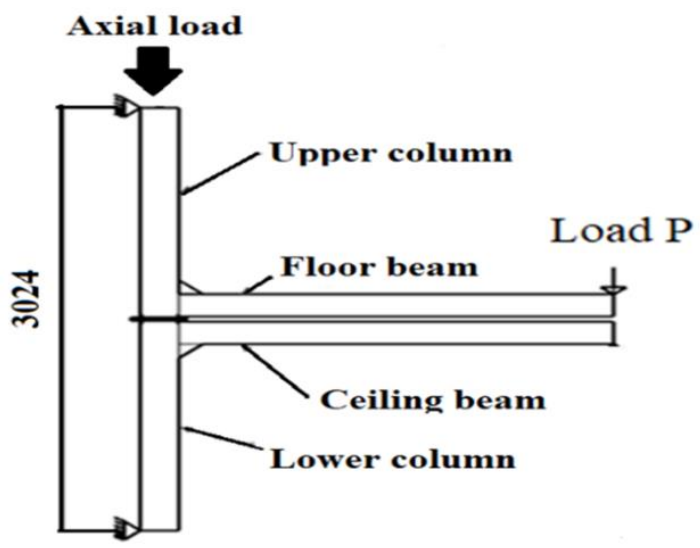

(b)

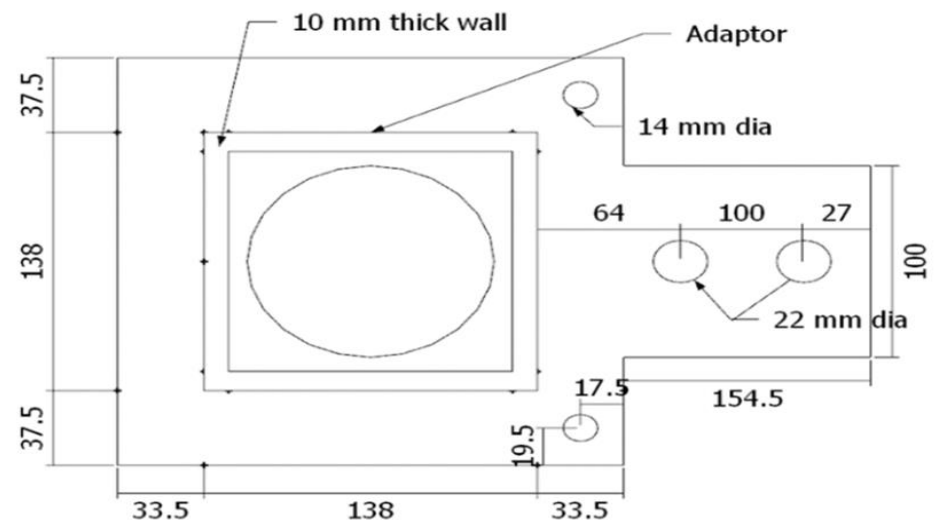

(c)
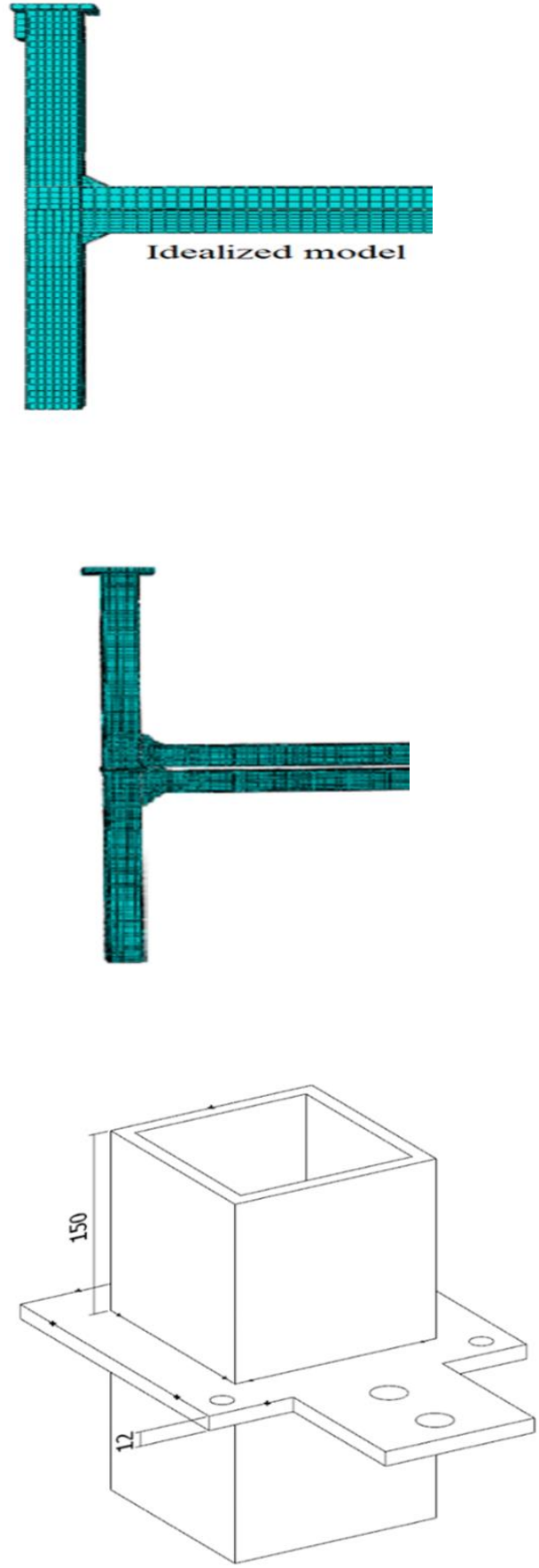

Figure 3. (a) Details of experimental specimen [18] and FE idealized model used in validation process, (b) specimen orientation of proposed connection and FE model idealization, and (c) details of the proposed connection.

A three-dimensional finite element model of connection is developed to represent the actual test configuration. Models consist of square hollow sections (SHS) and columns (200 $\times 200 \times 10 \mathrm{~mm})$ connected with a floor beam $(200 \times 180 \times 8 \mathrm{~mm})$ and a ceiling beam $(200$ $\times 180 \times 6 \mathrm{~mm}$ ). Joint boxes were connected with both upper and lower columns. The nonlinear analysis was conducted to capture analogous simulation results. Another 3D finite element model of the proposed connection was developed using similar numerical modeling techniques and material properties discussed in subsequent sections. The model 
consists of columns, floor beams, ceiling beams, and connections with all its components (adapter, plug plate, bolt, and spring) as illustrated in Figure 3b,c. Dimensions of all sections adopted in the model are provided in Table 1.

Table 1. Dimensions of sections for proposed connection.

\begin{tabular}{ccccc}
\hline Part & $\begin{array}{c}\text { Section } \mathbf{b} \times \mathbf{h} \\
\mathbf{( m m})\end{array}$ & $\begin{array}{c}\text { Thickness } \\
\mathbf{( m m )}\end{array}$ & $\begin{array}{c}\text { Length } \\
\mathbf{( m m )}\end{array}$ & $\begin{array}{c}\text { Plastic Moment } \\
\mathbf{M p} \mathbf{( k N m )}\end{array}$ \\
\hline Column & $160 \times 160$ & 10 & 1500 & 129.6 \\
Floor beam (Fbeam) & $160 \times 160$ & 8 & 1800 & 107.1 \\
Ceiling beam (Cbeam) & $160 \times 160$ & 6.3 & 1800 & 86.68 \\
\hline
\end{tabular}

\subsection{Elements Type and Meshing}

The nonlinear FE model was discretized by applying a suitable mesh element. All subassemblies (columns, beams, connection, and bolts) were modeled with second order isoparametric brick elements (hexahedral) due to the high accuracy that this element could provide. The gradient matrix [B] of these elements is provided in ABAQUS 6.14 [28] library and it is expressed in equation (1). The whole model can be meshed with first-order 8-node with reduced integration elements to save computing time, but due to Hour-glassing the result may be inaccurate. To reduce computing time, the model was assigned using two different nodes of similar element type: brick element C3D20R (20-node brick element with reduced integration) and C3D8R (8-node brick element with reduced integration). A second-order brick element C3D20R was used for the idealized highly sensitive region such as column-beam joint, connections, and bolts where large deformations expected to occur, and C3D8R brick elements were used in the remaining portion of the model. To capture better bending results of main members (columns and beams), the elements were refined in the thickness direction of the members, i.e., at least two elements used in the thickness direction. Same as the element type, the size of elements also varied according to the region in the model. The selection of mesh density was based on the mesh sensitivity study, as summarized in Table 2.

Table 2. Mesh sensitivity study on a 3D nonlinear model in ABAQUS.

\begin{tabular}{|c|c|c|c|c|c|c|}
\hline \multicolumn{2}{|c|}{ Element Type } & \multicolumn{2}{|c|}{ Size of Elements (mm) } & \multirow[b]{2}{*}{$\begin{array}{l}\text { Total Number } \\
\text { of Elements }\end{array}$} & \multirow[b]{2}{*}{$\begin{array}{c}\text { Total } \\
\text { Computing } \\
\text { Time (Minutes) }\end{array}$} & \multirow[b]{2}{*}{$\begin{array}{c}\text { Ultimate } \\
\text { Moment } \\
(\mathrm{kNm})\end{array}$} \\
\hline $\begin{array}{c}\text { Area of } \\
\text { Interest } \\
\text { (Joint Panel) }\end{array}$ & Other Parts & $\begin{array}{c}\text { Area of } \\
\text { Interest } \\
\text { (Joint Panel) }\end{array}$ & Other Parts & & & \\
\hline C3D20R & C3D8R & 15 & 25 & 29,100 & 120 & 289.3 \\
\hline C3D20R & C3D20R & 15 & 15 & 53,361 & 1440 & 291.6 \\
\hline C3D20R & C3D8R & 30 & 30 & 11,339 & 45 & 295.5 \\
\hline C3D20R & C3D8I & 15 & 25 & 29,100 & 150 & 291.3 \\
\hline
\end{tabular}

Mesh sensitivity was conducted to select an appropriate mesh, which can produce acceptable simulation results with less computing time. It can be observed from Table 2 that by changing size of elements the ultimate moment capacity of the joint is also changed, this is because assigning smaller size mesh also increased the number of nodes per unit area or per unit volume, which can more precisely capture the deformation and stresses. An optimum mesh size of $15 \mathrm{~mm}$ is selected for the highly sensitive region, i.e., the region where the plastic hinges were expected to occur in the beams and the joint panel (area of interest) and $25 \mathrm{~mm}$ for the remaining parts. The number of elements near holes and at corners of the beam and column were kept denser. In total, 29,100 hexahedral elements were used in the model. 
In the uniform strain formulation, the gradient matrix $B_{i}^{I}$ is defined by integrating over the element as

$$
\begin{gathered}
B_{i}^{I}=\frac{1}{V_{e l}} \int_{V_{e l}} N_{i}^{I}(g, h, r) d V_{e l} \\
N_{i}^{I}(g, h, r)=\frac{\partial N}{\partial x_{i}}
\end{gathered}
$$

where $V_{e l}$ is the element volume, $i$ has a range of three and $g, h, r$ are the isoparametric element coordinates.

In the centroidal strain formulation the gradient matrix $B^{I}$ is simply given as

$$
B_{i}^{I}=N_{i}^{I}(0,0,0)
$$

where $N^{I}$ is the isoparametric shape functions and can be written as

$$
N^{I}(g, h, r)=\frac{1}{8} \sum^{I}+\frac{1}{4} g \Lambda_{1}^{I}+\frac{1}{4} h \Lambda_{2}^{I}+\frac{1}{4} r \Lambda_{3}^{I}+\frac{1}{2} h r \Gamma_{1}^{I}+\frac{1}{2} g r \Gamma_{2}^{I}+\frac{1}{2} g h \Gamma_{3}^{I}+2 g h r \Gamma_{4}^{I}
$$

The superscript $I$ denotes the node of the element. The last four vectors, $\Gamma_{\alpha}^{I}(\alpha$ has a range of four), are the hourglass base vectors, which are the deformation modes associated with no energy in the 1-point integration element but resulting in a nonconstant strain field in the element.

\subsection{Interaction}

Contact interaction between different surfaces needs to be defined to ensure appropriate behavior capture during analysis. Interaction properties are influencing how contact surfaces will behave when they come in contact with each other. Contact between two surfaces was assigned as master and slave surfaces; for each contact pair, the surfaces were defined such that the surfaces of rigid parts, parts taking loads, and parts with coarser mesh were assigned as master surfaces. The surface technique was used to define properties between the surfaces of the plates, bolt shank and bolt hole. An interaction property has penalty friction and hard contact for tangential behavior and normal contact, respectively, for surface contact between subassemblies. Welded parts were not modeled specifically; in ABAQUS, welded parts can be modeled using two methods using merging one part with another or by assigning tie constraints between parts. In this study, tie constraints were used for welded parts. The summary of interaction contact properties is provided in Table 3.

Table 3. Summary of contact interaction.

\begin{tabular}{cccc}
\hline Contact Pair & Contact Type & Tangential Behavior & Normal Behavior \\
\hline $\begin{array}{c}\text { Column with Beam } \\
\begin{array}{c}\text { Stiffener with column } \\
\text { and beam }\end{array}\end{array}$ & $\begin{array}{c}\text { Tie Constraint } \\
\text { Tie Constraint }\end{array}$ & - & - \\
Plates & $\begin{array}{c}\text { Surface-surface } \\
\text { contact interaction } \\
\text { Surface-surface } \\
\text { Bolt shank-hole }\end{array}$ & Penalty & Hard contact \\
Bolt head-cover plate & Tie Constraint & Penalty & Hard contact \\
\hline
\end{tabular}

\subsection{Material Modeling}

The entire collapse mechanism of the column-beam joint can either occur by yielding the joint panel (column failure) or by developing plastic hinges in connected beams, depending on design specifications [29]. In general, steel structure members are commonly made of hot-rolled steel, and properties of this type of steel may be adopted in the FE analysis. 
In finite element modeling, accurate and specific material modeling is required to produce the actual behavior of the real structure. Since the model is composed of steel material, a nonlinear steel behavior represented by the bi-linear stress-strain relationship was considered as illustrated in Figure 4 , where $E_{o}$ is Young's modulus, $E_{t}$ is tangent modulus. The plastic properties required to be defined as input in the material properties are: (a) a yield condition to specify the onset of plastic deformation, (b) a flow rule to define the plastic straining, and (c) a hardening rule to define the evolution of the yield surface with plastic straining. The yield condition was defined under the von Mises yield criterion as given in Equation (5). Flow rule defines the direction of plastic strain vector. The equivalent plastic strain (PEEQ) criterion was utilized, which can be expressed by Equation (6). For the hardening stage, isotropic hardening was assumed. The isotropic type of elasticity was selected, that is simplest form of linear elasticity is the isotropic case, and the stress-strain relationship is represented by [D] matrix as given in ABAQUS 6.14 material library [28] and expressed in Equation (7).

$$
\sigma_{v}=\sqrt{\frac{\left(\sigma_{1}-\sigma_{2}\right)^{2}+\left(\sigma_{2}-\sigma_{3}\right)^{2}+\left(\sigma_{1}-\sigma_{3}\right)^{2}}{2}}
$$

where $\sigma_{v}$ is von mises stress, $\sigma_{1}, \sigma_{2}$ and $\sigma_{3}$ is the normal stress $\mathrm{x}, \mathrm{y}$ and $\mathrm{z}$ component respectively.

$$
\varepsilon^{p}=\sqrt{\frac{2}{3} \varepsilon^{p l} i j \varepsilon^{p l} i j}
$$

where $\varepsilon^{p}$ is PEEQ, $\varepsilon^{p l}$ is plastic strain and $i_{j}$ is strain tensor.

$$
[D]=\left\{\begin{array}{l}
\varepsilon_{11} \\
\varepsilon_{22} \\
\varepsilon_{33} \\
\gamma_{12} \\
\gamma_{13} \\
\gamma_{23}
\end{array}\right\}=\left[\begin{array}{cccccc}
\frac{1}{E} & \frac{-v}{E} & \frac{-v}{E} & 0 & 0 & 0 \\
\frac{-v}{E} & \frac{1}{E} & \frac{-v}{E} & 0 & 0 & 0 \\
\frac{-v}{E} & \frac{-v}{E} & \frac{1}{E} & 0 & 0 & 0 \\
0 & 0 & 0 & \frac{1}{G} & 0 & 0 \\
0 & 0 & 0 & 0 & \frac{1}{G} & 0 \\
0 & 0 & 0 & 0 & 0 & \frac{1}{G}
\end{array}\right]\left\{\begin{array}{l}
\sigma_{11} \\
\sigma_{22} \\
\sigma_{33} \\
\sigma_{12} \\
\sigma_{13} \\
\sigma_{23}
\end{array}\right\}
$$

where $E$ is Young's modulus, $v$ is poisson ratio and $G$ is shear modulus.

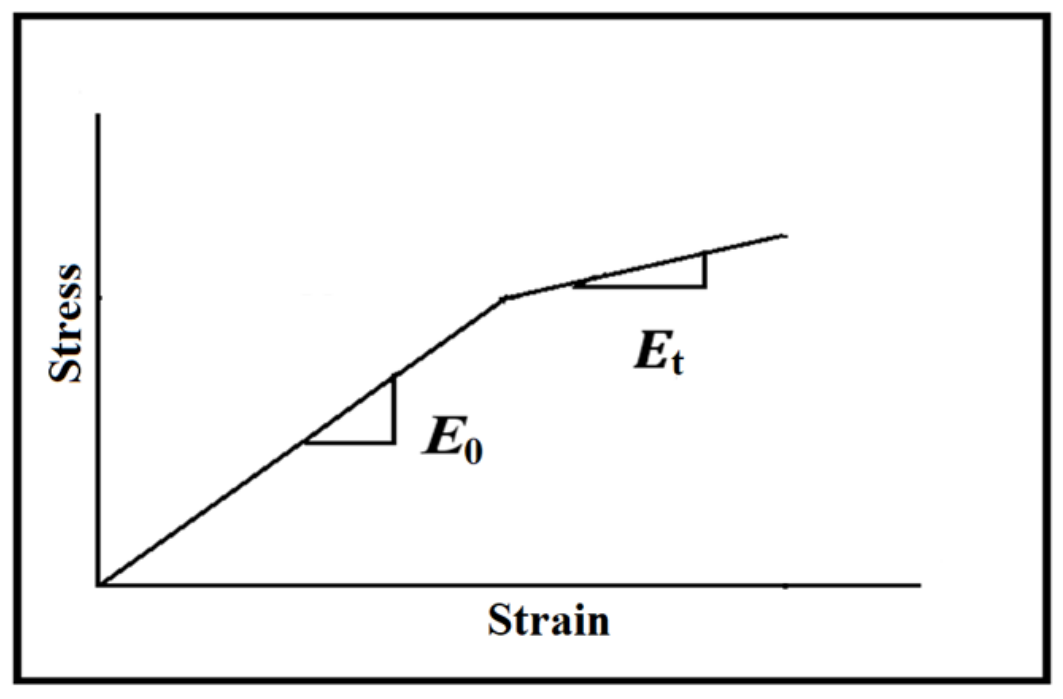

Figure 4. Bilinear hardening stress-strain curve redrawn from [30].

\subsection{Analysis and Step Procedures}

In ABAQUS software, an analysis can be performed by defining one or more than one step. At the same time, each step is further divided into multiple increments. There are two 
types of steps: general/standard steps, which are used for the linear and nonlinear problem, and linear perturbation steps, which can be used only to analyze the linear response.

To determine the structural behavior of nonlinear problems, a general/standard procedure step was assigned; this procedure is suitable for static nonlinear problems. The total load applied in a step is divided into increments, automatically calculated from the initial increment size according to convergence and accuracy conditions. A size of 0.1 was assigned as an initial increment. Vertical increment equation for equilibrium is solved by the Newton method; an iterative scheme eradicates the residuals for every step. The incremental iterative followed by Newton method is presented in Figure 5. The stiffness matrix [k] for each iteration can be expressed as given in Equation (10).

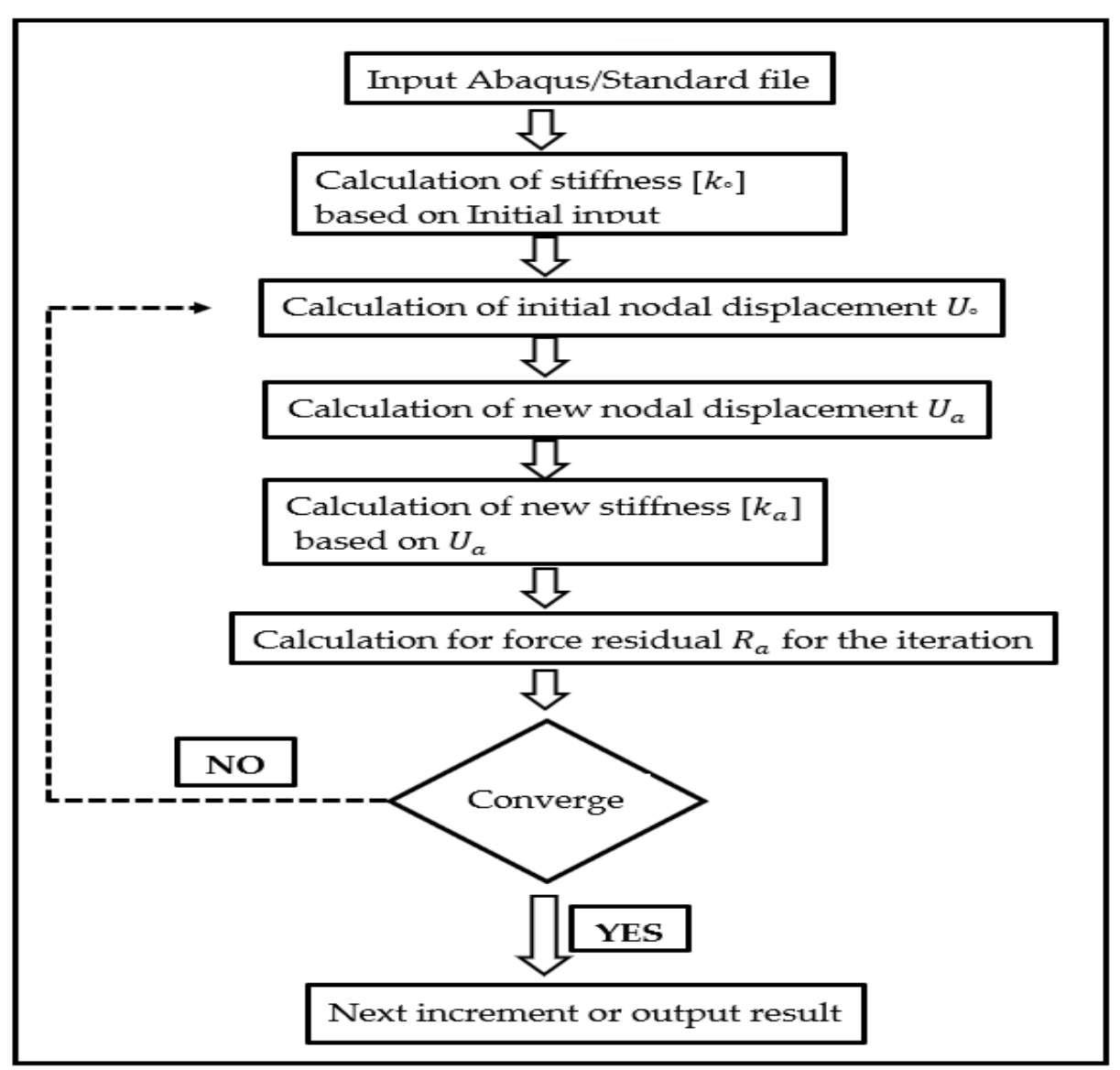

Figure 5. The incremental iterative Newton scheme in Abaqus/Standard.

According to Hooke's law,

$$
F=K . d
$$

or

$$
\{F\}=[K]\{d\}
$$

where $F$ is the global nodal force vector, $d$ is called the global nodal displacement vector, and $K$ is called the global stiffness matrix.

For a 3D element matrix $[K]$ can be expressed as

$$
[K]=\iiint[B]^{T}[D][B] d v
$$


where $[B]$ and $[D]$ are given in Equations (1) and (5), respectively.

$$
\begin{gathered}
F=\left\{\begin{array}{c}
F_{1 x} \\
F_{1 y} \\
F_{1 z} \\
\cdot \\
\cdot \\
F_{n x} \\
F_{n y} \\
F_{n z}
\end{array}\right\} \\
d=\left\{\begin{array}{c}
d_{1 x} \\
d_{1 y} \\
d_{1 z} \\
\cdot \\
\cdot \\
d_{n x} \\
d_{n y} \\
d_{n z}
\end{array}\right\}
\end{gathered}
$$

\section{Validation of FE Model}

To verify FE modeling techniques, a comparison between the FE model and experimental results has been conducted. For this purpose, experimental results obtained by [18] were used. The moment-drift ratio data were obtained from reference study by utilizing image digitization technique, while FE model data were obtained by importing output data from ABAQUS to Microsoft Excel. The specimen configuration, support conditions and its geometrical section and FE idealization, are shown in Figure 3a. The support conditions of these experimental specimens were pinned at both ends of the column, and beams' ends were free to move in the direction of the load. To simulate actual behavior in FE, appropriate boundary conditions were applied to the model as illustrated in Figure 6a. Mechanical properties of materials of the experimental specimen are shown in Table 4. The theoretical tensile yield strength of $640 \mathrm{MPa}$ and ultimate tensile strength of $880 \mathrm{MPa}$ was used for bolts [31].

In reference study [18], the design assumptions of the specimen were considered that sections of beams would affect the seismic behavior of joints, as most plastic deformation occurred on the root of the beam. This study focused on the global and local performance of column beam joints based on these design criteria. The results of FE modeling and experimental were compared in terms of the moment and drift ratio $(\mathrm{M}-\theta)$ curve as shown in Figure $6 \mathrm{~b}$. The overall response of the FE curve agrees well with the experimental data. This $\mathrm{M}-\theta$ curve is commonly categorized by an initial stiffness phase that is followed by the second phase of much-reduced stiffness. From the observation, both curves initially remain in an elastic state up to a moment of $218 \mathrm{kNm}$. Afterward, both curves entered a nonlinear state, after that moment peaked $289 \mathrm{kNm}$ for experimental and $290 \mathrm{kNm}$ for FE model. Afterward, both curves showed a descending trend.

In terms of physical observation, a gap between upper and lower columns was observed at the outer region of connection boxes in FE model; this was identical to what was observed in experimental work. A gap of 3 and $3.58 \mathrm{~mm}$ produced between upper and lower connection boxes in experimental and FE model respectively as shown in Figure 6c. FE model produced local buckling at web and flange of root ceiling beam similar to observed in the experimental test as illustrated in Figure 6d. This behavior shown good agreement results between experimental and FE studies. Therefore, FE modeling used in this study was able to well simulate the actual performance of the experimental work. 


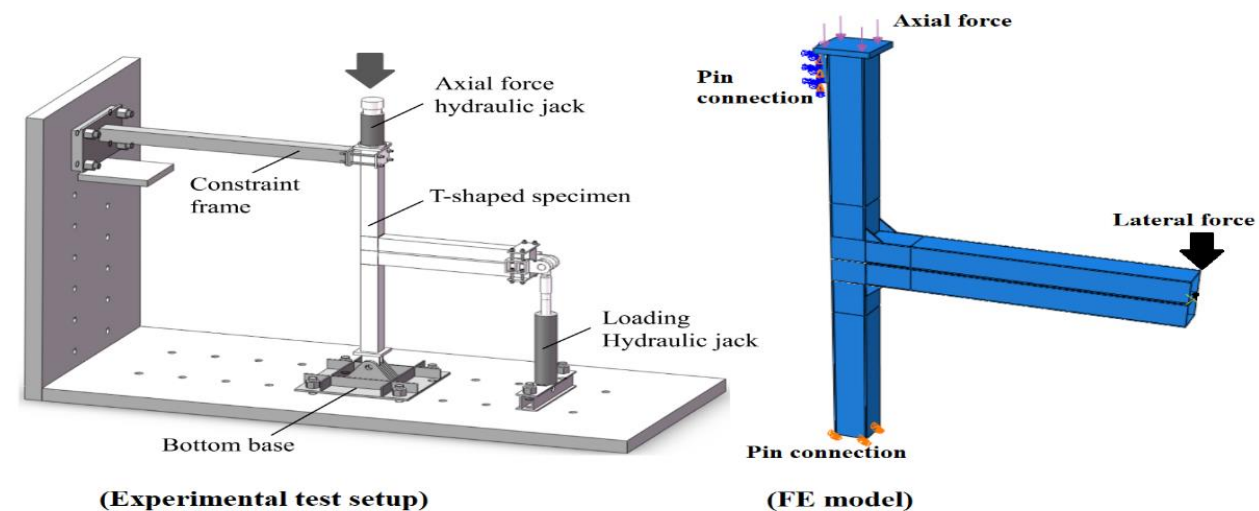

(a)

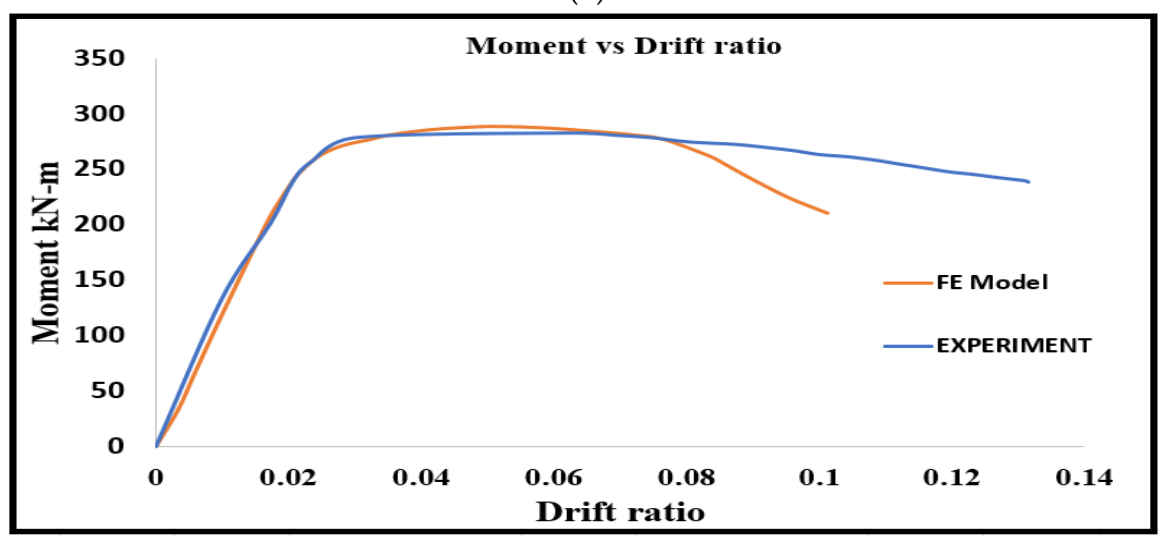

(b)
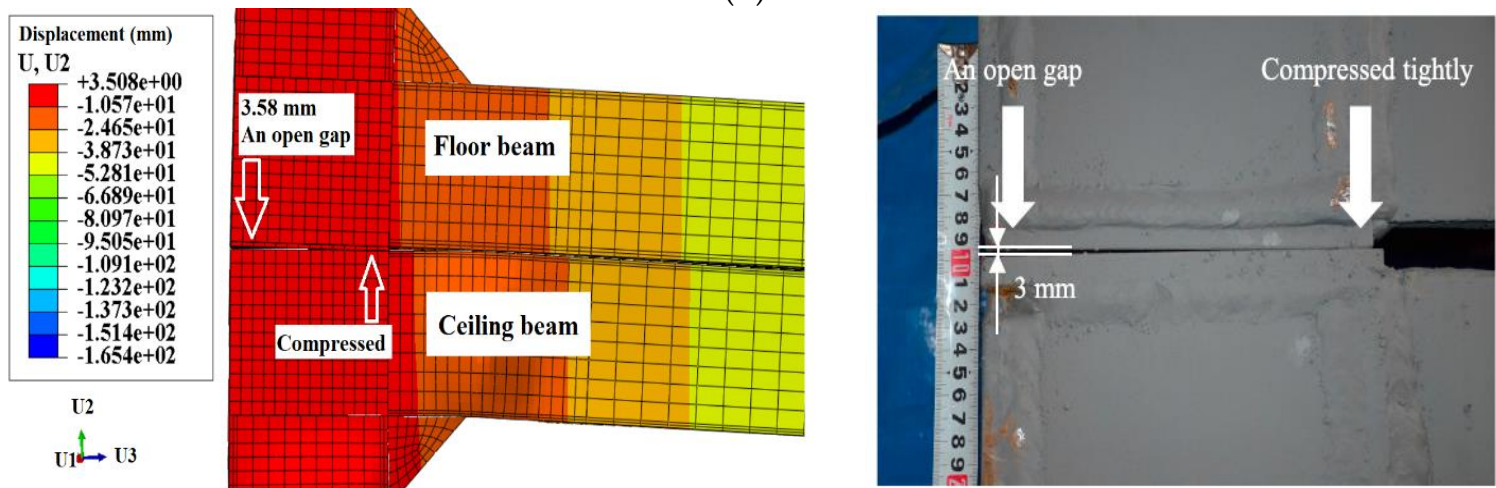

(c)
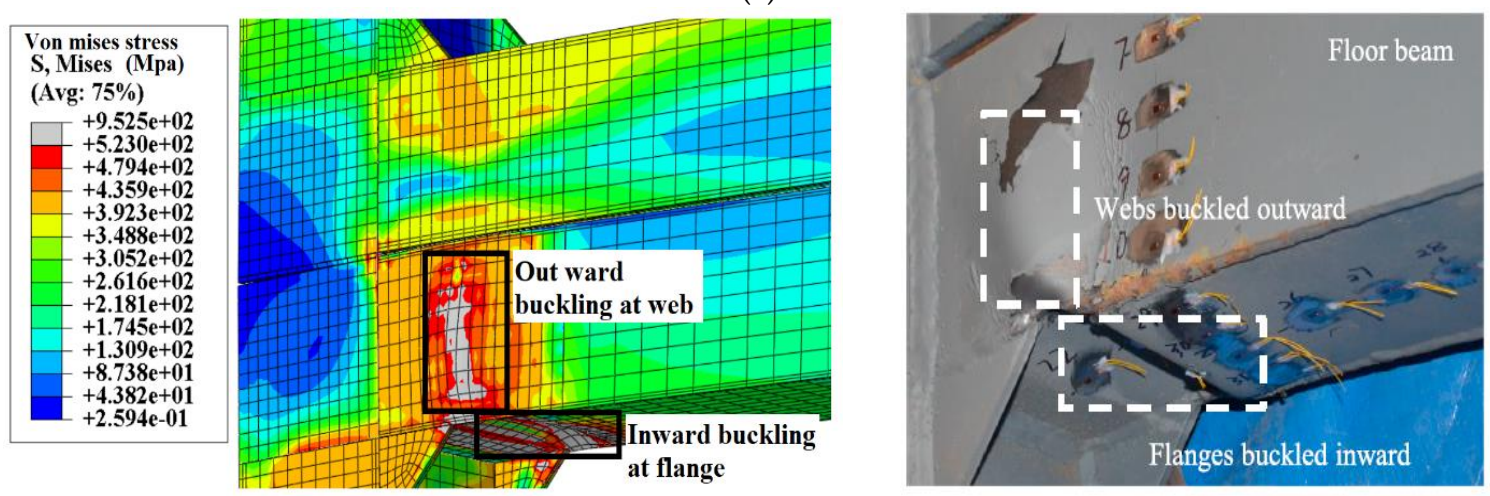

(d)

Figure 6. Comparison between experimental observations [18] and FE model. (a) Test setup. (b) Moment vs. drift ratio curve. (c) Opening between lower and upper connection box. (d) Local buckling at root of ceiling beam. 
Table 4. Mechanical properties of materials [18].

\begin{tabular}{|c|c|c|c|c|c|c|}
\hline Parts & Steel Grade & $\begin{array}{c}\text { Elastic } \\
\text { Modulus } \\
\text { (Gpa) }\end{array}$ & $\begin{array}{l}\text { Yield Strength } \\
\text { (Mpa) }\end{array}$ & $\begin{array}{c}\text { Ultimate } \\
\text { Strength (Mpa) }\end{array}$ & Elongation (\%) & $\begin{array}{c}\text { Poisson Ratio } \\
\text { (v) }\end{array}$ \\
\hline $\begin{array}{l}\text { Beam and } \\
\text { column }\end{array}$ & Q345B & 195.8 & 393.8 & 523.5 & 33.8 & 0.3 \\
\hline $\begin{array}{l}\text { Component of } \\
\text { connectors }\end{array}$ & U20452 (45\#) & 193.3 & 441.3 & 553.7 & 30.6 & 0.3 \\
\hline Bolt & 8.8 & 210 & 640 & 880 & 12 & 0.3 \\
\hline
\end{tabular}

\section{Parametric Study on the Proposed Connection}

The seismic performance of a building is highly affected by the strength and stiffness of the column beam joint. In current codes [32,33], a joint may be classified as rigid, nominally pinned, or semi-rigid according to its rotational stiffness capacity. For a bolted connection, the surface conditions of connecting plates and pretension force applied to the bolts influence the initial stiffness of the connection. However, the size of the section affects the rotation capacity of a joint. As for the proposed connection, it is involved a dual bolted and plug-in connection. Therefore, it is essential to know the factors that can affect the proposed connection's performance under lateral load and as well as under axial tensile load. A parametric study presented here is divided into two parts representing by 10 FE models of various combination parameters as indicates in Table 5. There are four different parameters evaluated in this parametric study namely as spring pin and bolt, bolt pretensioned load, thickness of beam and coefficient of friction. In the first part (Cp2 and Cp3), the effect of the spring pin and bolt at the outer face of the column was evaluated. Boundary conditions for this setup were selected as pinned support at the bottom of the lower column and the ends of beams. The beams were allowed to rotate in the loading direction only while an axial tension load was applied on the top upper column [24]. While in the second part (Cp1, Cp4, Cp5, Cp6, Cp7, Cp8, and Cp9), the moment-rotation curve under lateral load was computed by changing different parameters.

Table 5. Designation of models in parametric study with associated parameter and its range.

\begin{tabular}{ccc}
\hline Models & Parameters & Range \\
\hline Cp2, Cp3 & Spring pin dan bolt & With and without spring pin \\
\hline Cp1, Cp6, Cp7 & Bolt pretensioned & 35.6 to $53.5 \mathrm{kN}$ \\
\hline $\mathrm{Cp} 1, \mathrm{Cp} 4, \mathrm{Cp} 5$ & $\begin{array}{c}\text { Thickness of beam ratio (floor } \\
\text { beam/ ceiling beam) }\end{array}$ & $8 / 6.3,14 / 12.5,10 / 10$ \\
\hline $\mathrm{Cp} 1, \mathrm{Cp} 8, \mathrm{Cp} 9$ & $\begin{array}{c}\text { Coefficient of friction between } \\
\text { all contact surface of friction }\end{array}$ & $0.19,0.23,0.27$ \\
\hline
\end{tabular}

(i) Bolt pretension load: The bolt pretension load is applied with different ranges of snug tightening. The applied bolt load was calculated according to Equation (13) obtained from Eurocode 3 [32].

$$
F_{p c d}=0.7 f_{u b} * A_{s} / \gamma_{M 7}
$$

where $F_{p c d}$ is designed to preload force, $f_{u b}$ is the ultimate tensile strength of the bolt, $A_{s}$ is the tensile stress area of the bolt, and $\gamma_{M 7}$ is taken as 1.1.

(ii) Thickness of beams: Another parameter considered is the thickness of beams which were selected from a range of joints to satisfy the condition of "strong column-weak beam" joint to the condition of "weak column-strong beam" joint, this range was selected to know the seismic behavior of proposed connection in both conditions.

(iii) Coefficient of friction $\mu$. The coefficient of friction was modified from 0.19 to 0.23 and then 0.27 between all contact surfaces in the model, i.e., plates to the column, SHS sidewalls, and bolt surfaces. These values reflect varying forms of surface treatment, 
varying from painted to nearly black steel. By removing paints at the surface of SHS with hand wire brushing or mild abrasive brushing, the friction coefficient $\mu$ between touch surfaces may also be improved [34]. Details of parameters adopted in models are given in Table 6.

Table 6. Details of models developed in ABAQUS.

\begin{tabular}{|c|c|c|c|c|c|}
\hline \multicolumn{6}{|c|}{ Parameters/Variables } \\
\hline Model ID & Load Type & $\begin{array}{l}\text { Bolt } \\
\text { Pretention } \\
\quad(k N)\end{array}$ & $\begin{array}{l}\text { Coefficient } \\
\text { of Friction } \\
(\mu)\end{array}$ & Spring/Stud & $\begin{array}{c}\text { Beam Thickness } \\
\text { Ratio } \\
\text { (Floor Beam/Ceiling } \\
\text { Beam) }\end{array}$ \\
\hline Cp1 & Static load at beam end & 35.6 & 0.23 & Yes & $8 / 6.3$ \\
\hline Cp2 & Load in tension on upper column & 78.5 & 0.23 & Yes & $8 / 6.3$ \\
\hline Cp3 & Load in tension on upper column & 78.5 & 0.23 & No & $8 / 6.3$ \\
\hline $\mathrm{Cp} 4$ & Static load at beam end & 35.6 & 0.23 & Yes & $14 / 12.5$ \\
\hline Cp5 & Static load at beam end & 35.6 & 0.23 & Yes & $10 / 10$ \\
\hline Cp6 & Static load at beam end & 17.18 & 0.23 & Yes & $8 / 6.3$ \\
\hline Cp7 & Static load at beam end & 53.5 & 0.23 & Yes & $8 / 6.3$ \\
\hline Cp8 & Static load at beam end & 35.6 & 0.19 & Yes & $8 / 6.3$ \\
\hline Cp9 & Static load at beam end & 35.6 & 0.27 & Yes & $8 / 6.3$ \\
\hline
\end{tabular}

Before discussing the parametric study results, the results of typical proposed section subjected to static vertical load are presented.

\subsection{Behavior of Proposed Connection (Cp1) under Static Lateral Loading}

The control model of the proposed connection represented by model Cp1 behaved in an elastic manner up to the moment of $192 \mathrm{kNm}$ and inter-story drift ratio of 0.021 radian; at this stage, initial stiffness was $8835 \mathrm{kNm} / \mathrm{rad}$ as shown in Figure 6a. Relative movement between adapter and column was noticed that was due to differences in the internal dimensions of column and tolerance of adapter. With further increase in applied loading, the yield began to develop at the root of the ceiling beam, and the slope of the $\mathrm{M}-\theta$ curve changed. The moment-rotation response increased gradually in the yield development stage. The joint reached its maximum moment capacity of $287 \mathrm{kNm}$ at 0.055 radian drift ratio, while at 0.04 radian, the moment of $274 \mathrm{kNm}$ was recorded, which was 0.96 of maximum moment carried by joint (satisfying requirement of special moment frame, SMF [33]). Joint showed an equilibrium condition until the yielding of ceiling beam achieved. After the yield developed in the ceiling beam, the walls of the adapter came in to contact with respective columns (this was because of the difference in the rotation between the ceiling and floor beams) and produced bearing stress on the walls of adapters; these stresses start to develop at the corners of adapter walls and propagate toward opposite direction as shown in Figure $7 \mathrm{~b}$. The bolt joining upper column and adapter, and spring pin also developed stress in shear. It is shown in Figure 7a that the initial stiffness rotation of the proposed joint is falling between the rigid and pinned connection and can be categorized as a semi-rigid connection according to Eurocode 3 (EC3) [32]. 


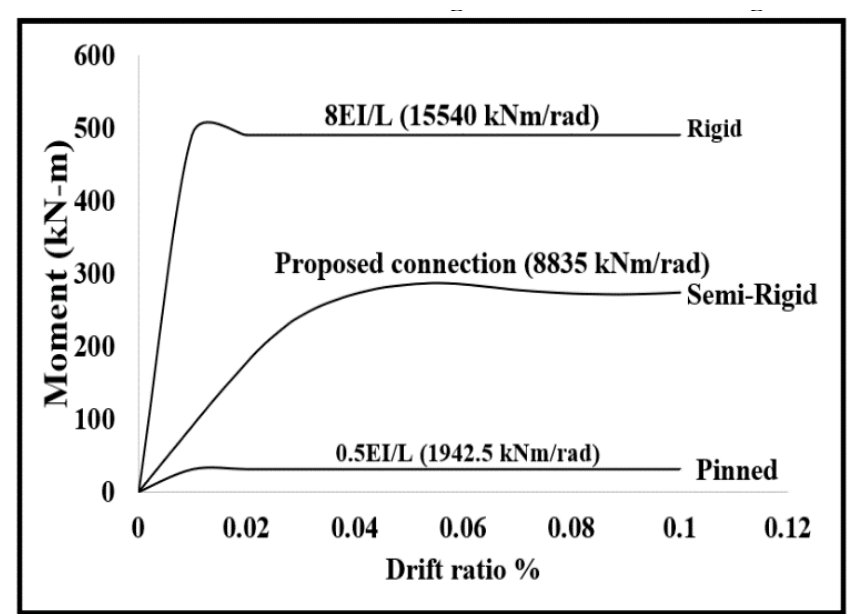

(a)

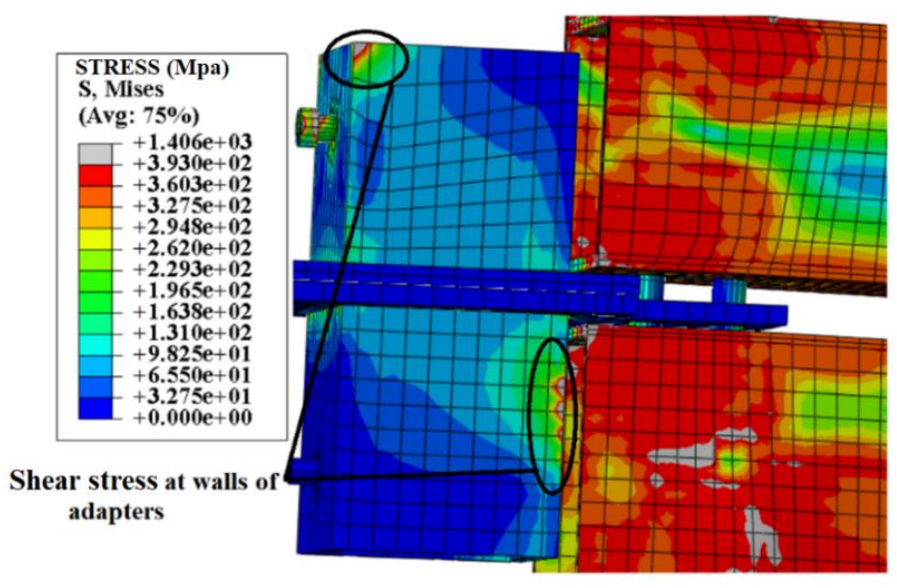

(b)

Figure 7. (a) Classification of joint according to EC3. (b) Shear stresses on the wall of the adapter.

\subsection{Connection under Axial Tension}

The structural performance of the proposed connection under axial tensile load was influenced by the presence of spring pin and bolt, and it has been studied using model $\mathrm{Cp} 2$ (with spring pin and outer bolt) and Cp3 (without spring pin and outer bolt). The observation on the gap separation between lower columns and connection is the primary findings. Figure 8a shows the axial tensile load vs. vertical displacement (separation among columns) between models $\mathrm{Cp} 2$ and $\mathrm{Cp} 3$. Initially, both connections show a linear relationship up to $210 \mathrm{kN}$ with a negligible separation. At this stage, the resistance to separation between lower and upper columns was due to the tensile resistance of long vertical bolts connecting both floor and ceiling beams. The perpendicular distance between long bolt and point of loading influences the separation between column and connection. The shorter the distance, the higher will be the resistance to separation [24]. After the load reached $250 \mathrm{kN}$, a significant difference in the direction of the curve was noticed. Shank of the outer bolt and spring pin in connection $\mathrm{Cp} 2$ at this stage came in contact with internal walls of bolt holes and started to resist further separation. The difference between curves increased with the increasing load, as shown in Figure 8a. The outer bolt and spring pins were under shear stresses while long bolts were under tensile stress. At a separation of 6 $\mathrm{mm}$, as shown in Figure 8a model Cp2 was able to carry a tensile load of $405 \mathrm{kN}$, whereas model Cp3 carried a tensile load of $250 \mathrm{kN}$. This indicates that the presence of the spring pin and outer bolt provided a major contribution to the tensile capacity of connection by $62 \%$, at the separation of $6 \mathrm{~mm}$. This difference was increasing when the separation was kept increasing up to $9 \mathrm{~mm}$. The separation between connection and the lower column was noticed, followed by the deformation of the long bolt and local deformation of the ceiling beam in connection Cp3, while in Cp2 connection, an additional shear deformation on outer bolt and pin occurred. 


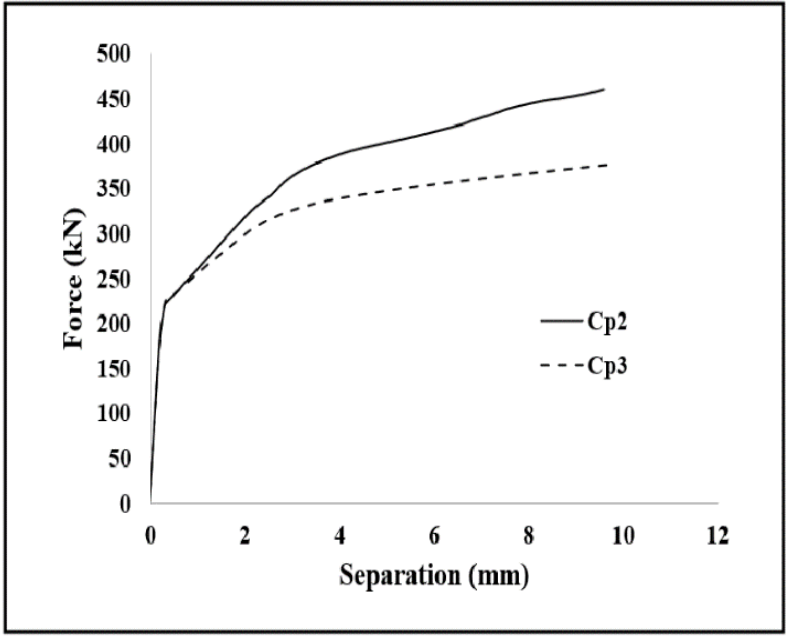

(a)

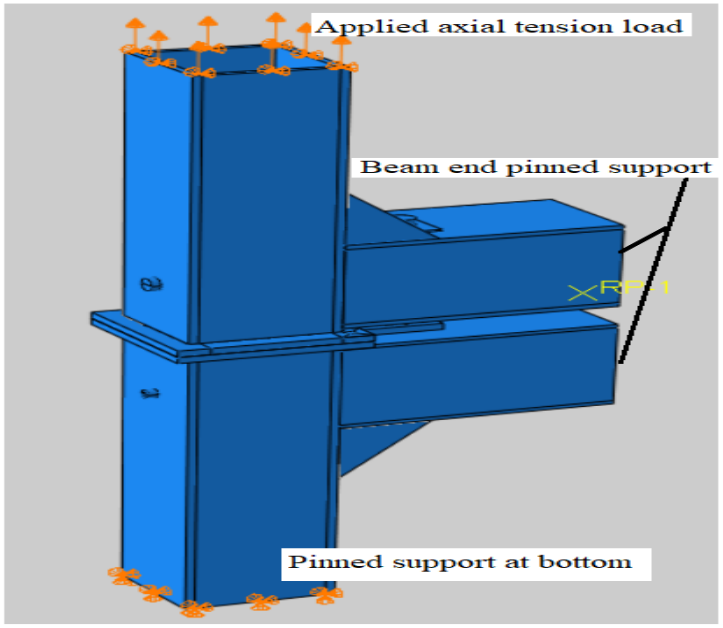

(c)

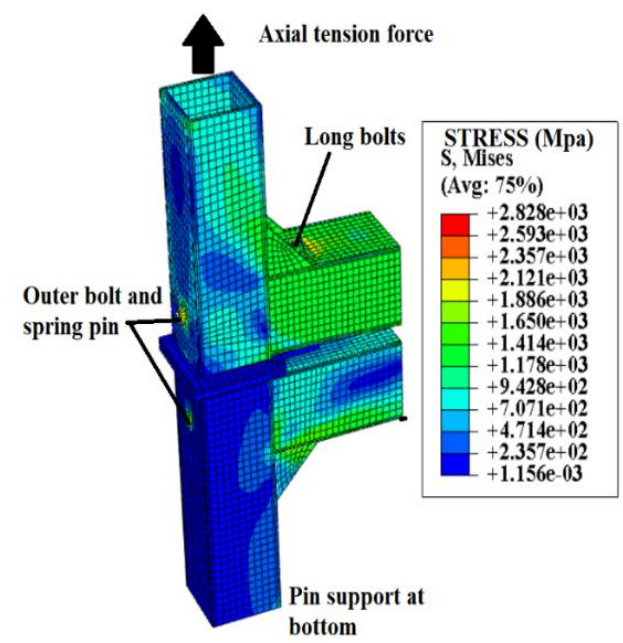

(b)

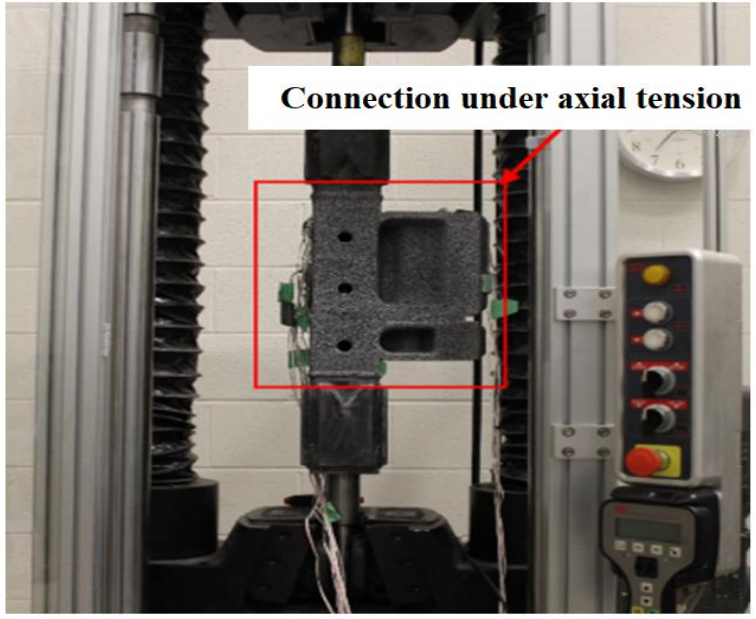

(d)

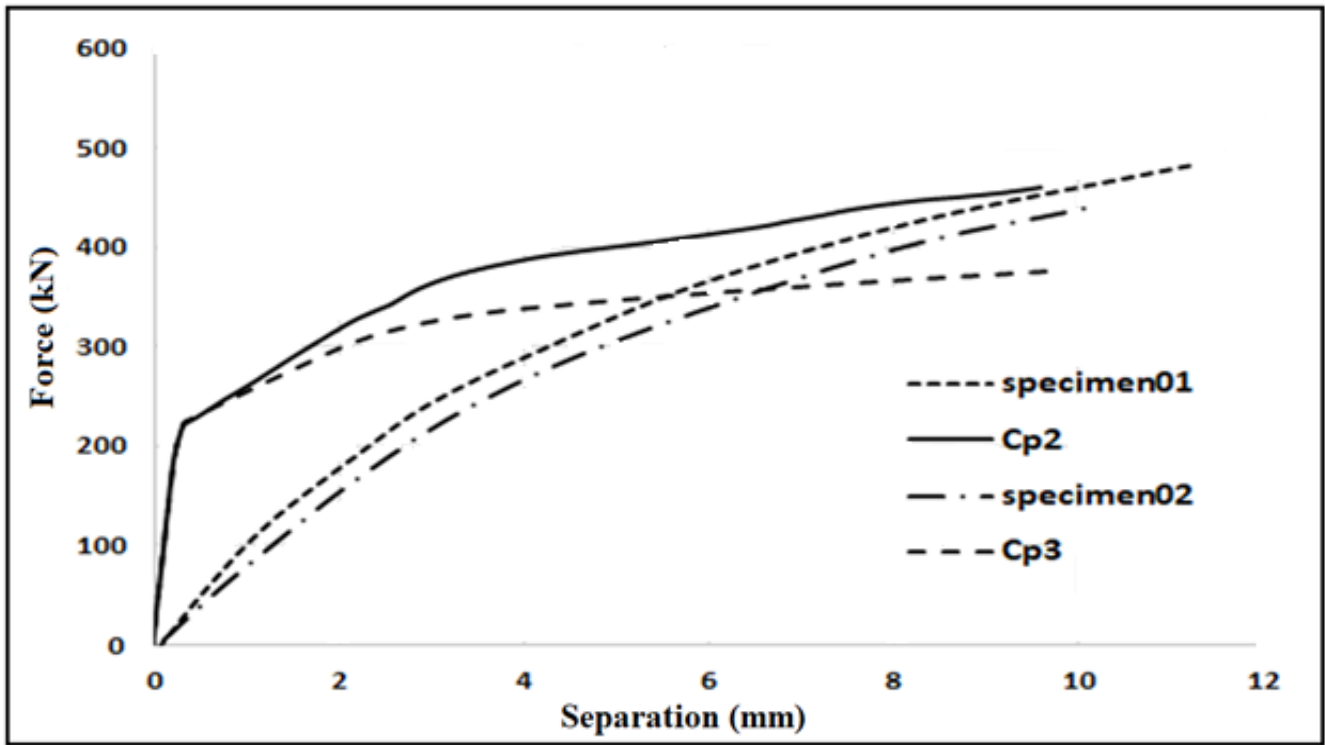

(e)

Figure 8. (a) Gap between column and connection under axial tension. (b) Stress distribution on joint. (c) Boundary conditions in FE model. (d) Test setup of column specimen 01 and 02 in tension [24]. (e) Force-separation displacement curve comparison between proposed connection and vector bloc [24]. 


\section{Comparison with an Existing Connection}

To evaluate the behavior of the proposed connection and effectiveness of spring pin, a comparison can be made with the behavior of existing inter-modular connection under axial tension reported in the literature. For the sake of comparison, the force vs. separation curve, as shown in Figure 8e, produced from proposed connection models Cp2 and Cp3 and two identical vector blocs, i.e., specimen 01 and specimen 02 , were subjected to axial tensile load as reported in the experimental study of [24]. Each specimen consisted of upper and lower blocs; the upper bloc connected the ceiling beams to the column, whereas the lower bloc connected the column to the floor beams. The upper and lower blocs were connected by means of two high-strength socket head cap screws (SHCS), as illustrated in Figure 8d. In Figure 8e, it is illustrated that the proposed connection specimens showed an improved initial resistance by producing sharp stiffness in comparison to the selected existing intermodule connections. At a separation of $6 \mathrm{~mm}, \mathrm{Cp} 2$ carried a higher load $(410 \mathrm{kN})$ compared to Cp3 $(350 \mathrm{kN})$, specimen $01(360 \mathrm{kN})$, and specimen $02(335 \mathrm{kN})$. Reaching at the maximum load $(450 \mathrm{kN}), \mathrm{Cp} 2$ and specimen 01 produced a separation between column and connection of $9 \mathrm{~mm}$. The specimen 01 and specimen 02 were composed of solid cast-steel and did not show any local deformation in the connection. The ultimate load carrying capacity of specimen 01 and specimen 02 compared to their counterpart connections Cp1 and Cp2 was higher as illustrated in Figure 8e, whereas the proposed connection Cp1 and Cp2 were composed of hot rolled hollow sections and shown up local deformation around the bolt heads. In all the connections, the failure occurred due to the yielding of bolts and local deformation at connections.

\subsection{Effect of Beams Thickness}

To quantify beam thickness on the rotational capacity of joint, models Cp4 and Cp5 were developed. Selection of beam thickness was based on the assumptions of weak beam strong column, i.e., $\mathrm{Cp} 1$ (thickness of $C_{\text {beam }}$ is $6.3 \mathrm{~mm}$, the thickness of $F_{\text {beam }}$ is $8 \mathrm{~mm}$ ) to strong beam weak column, i.e., $\mathrm{Cp} 4\left(C_{\text {beam }}=12.5 \mathrm{~mm}, F_{\text {beam }}=14 \mathrm{~mm}\right)$, column and beams having same thickness were denoted by $\mathrm{Cp} 5\left(C_{\text {beam }}=F_{\text {beam }}=10 \mathrm{~mm}\right)$. While the thickness of the column for all connections were kept constant at $10 \mathrm{~mm}$. Figure 9 a shows that the rotational stiffness and moment carrying capacity of the joint increased significantly by increasing the thickness of beams. In joint Cp1, the ceiling beam was the critical member to carry maximum moment in the joint. After the yielding occurred in the ceiling beam, the moment-rotation (M- $\theta$ ) curve tends to descend, while in joint Cp4 and Cp5 maximum moment carried by column and joint failure was caused by local deformation of column flange as shown in Figure 9b.

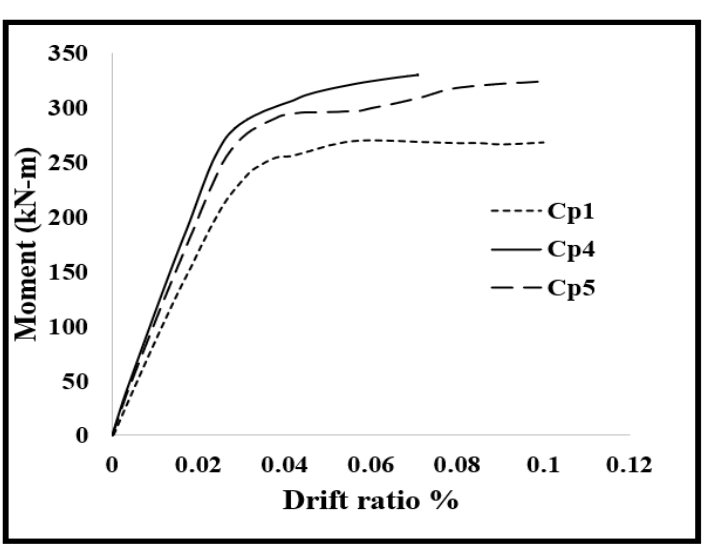

(a)

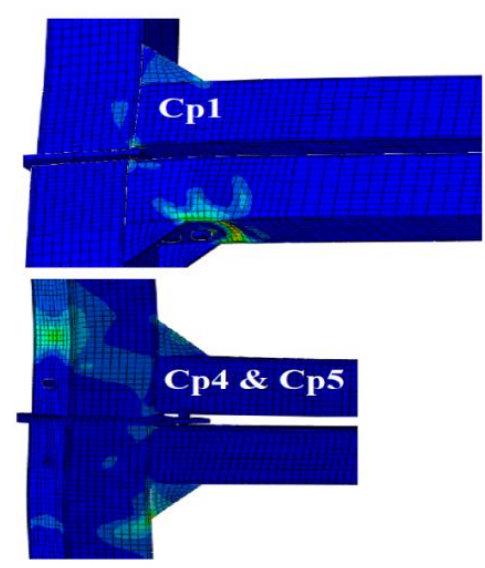

(b)

Figure 9. Effect of beam thickness (a) M- $\theta$ curve. (b) Location of failure. 


\subsection{Effect of Bolt Pretension}

Bolt pretension variability is considered since it may also be a possible issue in the practice of modular steel construction. Hollow steel section (HSS), where through bolts are used, are liable to inward point load, which can result in distortion of walls under the pretension force of bolt depending on the thickness of HSS. Due to the high flexibility of HSS walls, it is suggested to install bolts by means of snug tightening [35]. Three different pre-tensioning force levels for snug tightening were selected; $10 \%, 20 \%$, and $30 \%$ of the ultimate strength of bolt $f_{u}$, represented by model Cp6, Cp1, and Cp7, respectively. To study the bolt pretension, other parameters such as the size of the beam and column were kept constant as in Cp1. The initial stiffness and slip almost endured the same, or inelastic range pretension force did not significantly affect the behavior of joint. Bolt pretensions force up to $20 \%$ of the ultimate strength of bolt, which showed an increase in the moment carrying capacity of the joint. Further, an increase in pretension force results in decreasing moment capacity, as shown in Figure 10a. A further increase in pretension force caused the decrease in moment carrying capacity of joint. This was because of the local deformation in beams due to applied bolt load.

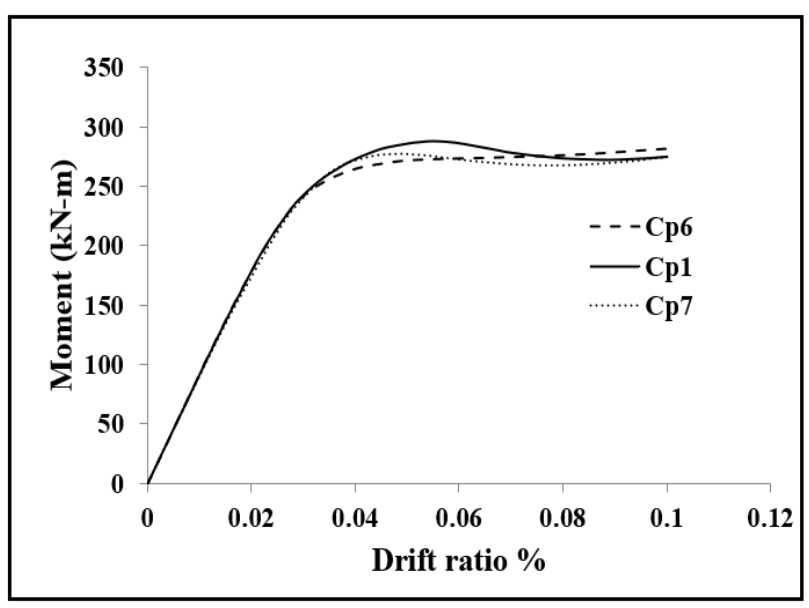

(a)

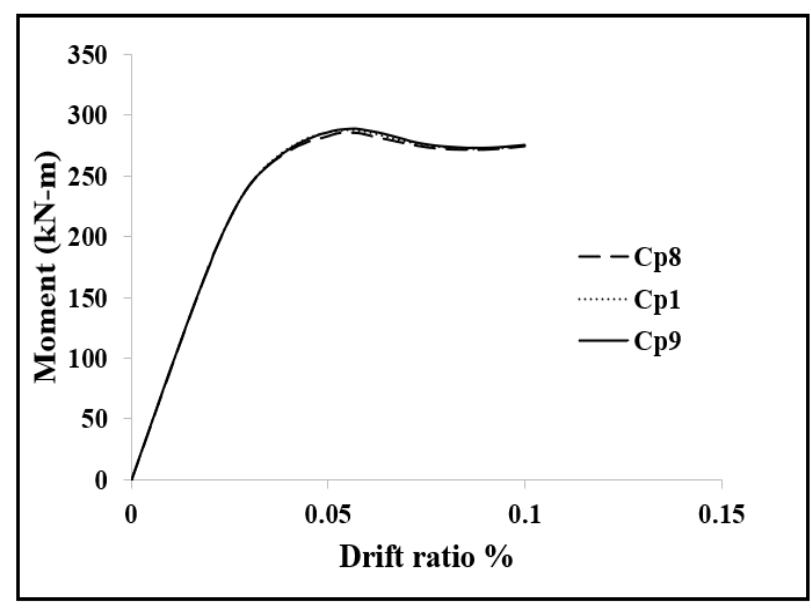

(b)

Figure 10. (a) Effect of bolt pretension. (b) Effect of coefficient of friction $\mu_{f}$.

\subsection{Effect of Coefficient of Friction, $\mu_{f}$}

To study the effect of the coefficient of friction on the behavior of the joint, three models were developed, namely $\mathrm{Cp} 8, \mathrm{Cp} 1$, and $\mathrm{Cp} 9$, to consider the coefficient of friction of $0.19,0.23$, and 0.27 , respectively. This coefficient of friction is imposed between the parts of connection, bolts, beams, and columns in finite element analysis. The above values of $\mu$ were selected for different surface treatment ranges, from painted to almost black steel surface $[31,34]$. From Figure 10b, varying values of $\mu_{f}$ did not significantly affect the initial rotational stiffness of joints, while an insignificant increase in moment carrying capacity was noticed for $\mu_{f}=0.27$.

\subsection{Ductility and Deformation Capacity}

Seismic design codes provide a well understanding of ductility and deformation capacity of the joint and guides for the appropriateness for seismic application. A drift ratio of 0.04 radian is required for Special Moment Frame (SMF) while 0.02 radian for Intermediate Moment Frame (IMF) in AISC seismic provisions [33]. Table 7 presents the related capacities of joint produced by all developed models. It comprises $M_{p i}$, which is defined as predicted moment capacity of joint which can be obtained by equation (14) [17]. $M_{y}$ is defined as yield moment, which taken as two-thirds of maximum moment $\left(M_{u}\right)$ [36], $M_{0.04}$ is moment at 0.04 radian, the ratio between $M_{0.04} / M_{u}$, the angular displacement 
coefficient $\left(\Delta_{d}\right)$, which is the ratio between maximum inter-story drift $\left(\theta_{y}\right)$ and yield interstory drift ratio $\left(\theta_{u}\right)$.

Table 7. Ductility and strength characteristics for all FE models.

\begin{tabular}{|c|c|c|c|c|c|c|c|c|c|c|}
\hline Joint ID & $M_{p c b}(\mathrm{kNm})$ & $M_{p f b}(\mathrm{kNm})$ & $M_{p i}(\mathrm{kNm})$ & $M_{u(F E M)}(\mathrm{kNm})$ & $M_{y_{(F E M)}}(\mathrm{kNm})$ & $M_{0.04}(\mathbf{k N m})$ & $\theta_{u}$ & $\theta_{y}$ & $\Delta_{d}$ & $\mathbf{M}_{0.04} / \mathbf{M}_{\mathbf{u}}$ \\
\hline Cp1 & 86.68 & 107.1 & 193.7 & 287 & 181 & 276 & 0.055 & 0.020 & 2.75 & 0.96 \\
\hline Cp4 & 155.6 & 171.7 & 327.3 & 327 & 218 & 306 & 0.060 & 0.020 & 3 & 0.93 \\
\hline Cp5 & 129.6 & 129.6 & 259.2 & 312 & 172.8 & 293 & 0.064 & 0.018 & 3.5 & 0.93 \\
\hline Cp6 & 86.68 & 107.1 & 193.7 & 273 & 182 & 266 & 0.060 & 0.020 & 3 & 0.97 \\
\hline Cp7 & 86.68 & 107.1 & 193.7 & 273 & 182 & 273 & 0.058 & 0.021 & 2.76 & 1.0 \\
\hline Cp8 & 86.68 & 107.1 & 193.7 & 284 & 189.3 & 272 & 0.059 & 0.021 & 2.80 & 0.95 \\
\hline Cp9 & 86.68 & 107.1 & 193.7 & 288 & 192 & 274 & 0.056 & 0.02 & 2.80 & 0.95 \\
\hline
\end{tabular}

It can be concluded from results provided in Table 7 that all joints were able to accommodate an inter-story drift ratio of a minimum of 0.02 radian at yielding except joint $\mathrm{Cp} 5$. Moreover, all joints produced a good performance in respect to drift ratio at yield and can maintain more than $80 \%$ of the maximum bending resistance beyond a deformation of 0.04 radian, as required for SMF systems in AISC. The ductility factor having a value of 2.5 is considered good plastic deformation ability of modular steel building connection [22] Table 7 summarized the ductility factor, $\Delta$ of joints presented in this study. The maximum value of $\Delta_{d}=3.5$ was observed for joint $\mathrm{Cp} 5$. The average ductility factor of all joints was 2.9 , which showed a satisfactory deformation pattern required for seismic design.

$$
\begin{gathered}
M_{p i}=M_{p c b}+M_{p f b} \\
M_{p}=f_{y} * \mathrm{Z}
\end{gathered}
$$

where $M_{p i}$ is the predicted bending resistance of the connection; $M_{p c b}$ and $M_{p f b}$ are the nominal moment capacity of the ceiling beam and floor beam, respectively, $f_{y}$ is yield stress and $\mathrm{Z}$ is the plastic section modulus.

\section{Conclusions}

This study proposed a self-locking connection to address the issues related to fixing intermodular connections between modules. This connection consists of adapters, center plate, a flat spring and long bolts. The proposed connection uses a flat spring mechanism and does not require extra workspace between modules. Finite element analysis was performed on the proposed connection design for modular steel building using ABAQUS software. The aim of the numerical study was to know the stress distribution among different connection components and to the understand the failure mode of structural members considering various parameters. The parametric study was conducted by varying beam thickness, bolt pretension force and friction coefficient $\mu$. The conclusions derived from the analysis are set below:

1. The proposed connection was able to maintain $80 \%$ of $\mathrm{Mu}$ at a drift ratio of 0.04 radian, hence meeting the criteria of ductility; therefore, it can be categorized as special moment frame (SMF) according to AISC. The initial stiffness ratio was leftover between the boundaries of the rigid connection and pinned connection; for that reason, the proposed connection can be characterized as a semi-rigid connection according to Eurocode 3.

2. The spring pin and outer bolt significantly mitigated the separation between column and connection under axial tension load. The proposed connection contributed sufficiently to carrying the bending moment produced at the joint; the upper and lower adapter has taken a load from the respective column by bearing action, which causes shear stress on the walls of the adapter.

3. Load carrying capacity and initial rotational stiffness of joint increased with an increase in thickness of floor and ceiling beams. Bolt pretension force was up to $20 \%$ of ultimate strength of the bolt shown, increasing moment carrying capacity of the joint, 
further increasing the pretension force, and resulting in a decreased moment capacity of the joint.

Author Contributions: Conceptualization, G.N.; methodology, G.N. and N.A.S.; software, G.N.; validation, G.N., N.A.S. and N.A.B.; formal analysis, G.N. and N.A.S.; investigation, I.A.K., N.A.B. and N.A.M.N.; resources, G.N. and N.A.S.; data curation, G.N. and N.A.S.; writing-original draft preparation, G.N. and N.A.S.; writing-review and editing, I.A.K., N.A.B. and N.A.M.N.; visualization, G.N. and N.A.S.; supervision, N.A.S., I.A.K. and N.A.B.; project administration, N.A.S.; funding acquisition, N.A.S. All authors have read and agreed to the published version of the manuscript.

Funding: This research was funded by Fundamental Research Grant Scheme, Ministry of Higher Education Malaysia (grant number: FRGS/1/2018/TK01/UPM/02/9).

Institutional Review Board Statement: Not applicable.

Informed Consent Statement: Not applicable.

Data Availability Statement: The data used to support the findings of this study are available from the corresponding author upon request.

Acknowledgments: The authors would like to thank the sponsor of this research which funded using Fundamental Research Grant Scheme (FRGS), Ministry of Higher Education of Malaysia with Grant number: FRGS/1/2018/TK01/UPM/02/9.

Conflicts of Interest: The authors declare no conflict of interest. The funders had no role in the design of the study; in the collection, analysis, or interpretation of data; in the writing of the manuscript; or in the decision to publish the results.

\section{References}

1. Navaratnam, S.; Ngo, T.; Gunawardena, T.; Henderson, D. Performance review of prefabricated building systems and future research in Australia. Buildings 2019, 9, 38. [CrossRef]

2. Nadeem, G.; Safiee, N.A.; Bakar, N.A.; Karim, I.A.; Nasir, N.A.M. Connection design in modular steel construction: A review. Structures 2021, 33, 3239-3256. [CrossRef]

3. Annan, C.D.; Youssef, M.A.; El Naggar, M.H. Assessment of overstrength and ductility of a four-story modular steel building braced frame. In Proceedings of the 2nd Canadian Conference on Effective Design of Structures McMaster University, Hamilton, ON, Canada, 20-23 May 2008.

4. Styles, A.J.; Luo, F.J.; Bai, Y.; Murray-Parkes, J.B. Effects of joint rotational stiffness on structural responses of multi-story modular buildings. In Proceedings of the International Conference on Smart Infrastructure and Construction; ICE Publishing: London, UK, 2016; pp. 457-462.

5. Wang, X.; Yuan, X.; Zeng, H.; Li, T.; Liang, Y.; Gao, X.; Yu, Y. Bearing Capacity and Failure Mode of a Light-Steel Tubular K-joint Connected by a Novel U-shape Connector. Appl. Sci. 2021, 11, 8587. [CrossRef]

6. Cho, B.H.; Lee, J.S.; Kim, H.; Kim, D.J. Structural performance of a new blind-bolted frame modular beam-column connection under lateral loading. Appl. Sci. 2019, 9, 1929. [CrossRef]

7. Wang, Y.; Xia, J.; Ma, R.; Xu, B.; Wang, T. Experimental study on the flexural behavior of an innovative modular steel building connection with installed bolts in the columns. Appl. Sci. 2019, 9, 3468. [CrossRef]

8. Sun, Y.; Wang, J.; Wu, J.; Shi, W.; Ji, D.; Wang, X.; Zhao, X. Constraints hindering the development of high-rise modular buildings. Appl. Sci. 2020, 10, 7159. [CrossRef]

9. Lacey, A.; Chen, W. Structural response of modular building subjected to earthquake loading. In Proceedings of the 13th International Conference on Steel, Space and Composite Structures, Western Australia, Perth, Australia, 31 January-2 February 2018.

10. Sultana, P.; Youssef, M.A. Seismic performance of modular steel-braced frames utilizing superelastic shape memory alloy bolts in the vertical module connections. J. Earthq. Eng. 2020, 24, 628-652. [CrossRef]

11. Paper, C.; Ontario, W.; Ontarioprofessor, W. Hysteretic characteristics of braced frames in modular steel buildings. In Proceedings of the Annual Conference-Canadian Society for Civil Engineering, London, UK, 1-4 June 2016; Volume 1.

12. Lacey, A.W.; Chen, W.; Hao, H.; Bi, K. Structural response of modular buildings - An overview. J. Build. Eng. 2018, 16, 45-56. [CrossRef]

13. Sultana, P.; Youssef, M.A. Seismic performance of modular steel frames equipped with shape memory alloy braces. Bull. Earthq. Eng. 2018, 16, 5503-5527. [CrossRef]

14. Annan, C.D.; Youssef, M.A.; El Naggar, M.H. Seismic overstrength in braced drames of modular steel buildings. J. Earthq. Eng. 2009, 13, 1-21. [CrossRef] 
15. Lacey, A.; Chen, W.; Hao, H.; Bi, K. Numerical study of the structural response to wind loading: Modular building case study. In Proceedings of the 13th International Conference on Steel, Space and Composite Structures, Western Australia, Perth, Australia, 31 January-2 February 2018; pp. 1-10.

16. Annan, C.D.; Youssef, M.; Naggar, M.H. Seismic performance of modular steel braced frames. In Proceedings of the 9th Canadian Conference on Earthquake Engineering, Ottawa, ON, Canada, 26-29 June 2007.

17. Deng, E.-F.; Zong, L.; Ding, Y.; Luo, Y.-B. Seismic behavior and design of cruciform bolted module-to-module connection with various reinforcing details. Thin-Walled Struct. 2018, 133, 106-119. [CrossRef]

18. Dai, X.M.; Zong, L.; Ding, Y.; Li, Z.X. Experimental study on seismic behavior of a novel plug-in self-lock joint for modular steel construction. Eng. Struct. 2019, 181, 143-164. [CrossRef]

19. Chen, Z.; Liu, J.; Yu, Y.; Zhou, C.; Yan, R. Experimental study of an innovative modular steel building connection. J. Constr. Steel Res. 2017, 139, 69-82. [CrossRef]

20. Hwan Doh, J.; Ho, N.M.; Miller, D.; Peters, T.; Carlson, D.; Lai, P. Steel Bracket Connection on Modular Buildings. J. Steel Struct. Constr. 2017, 2. [CrossRef]

21. Lee, S.; Park, J.; Shon, S.; Kang, C. Seismic performance evaluation of the ceiling-bracket-type modular joint with various bracket parameters. J. Constr. Steel Res. 2018, 150, 298-325. [CrossRef]

22. Chen, Z.; Liu, J.; Yu, Y. Experimental study on interior connections in modular steel buildings. Eng. Struct. 2017, 147, 625-638. [CrossRef]

23. Sendanayake, S.V.; Thambiratnam, D.P.; Perera, N.; Chan, T.; Aghdamy, S. Seismic mitigation of steel modular building structures through innovative inter-modular connections. Heliyon 2019, 5, e02751. [CrossRef]

24. Dhanapal, J.; Ghaednia, H.; Das, S.; Velocci, J. Structural performance of state-of-the-art VectorBloc modular connector under axial loads. Eng. Struct. 2019, 183, 496-509. [CrossRef]

25. Lawson, M. Building Design using Modules; The Steel Construction Institute: Ascot, UK, 2007; pp. 1-16.

26. Annan, C.D.; Youssef, M.A.; El-Naggar, M.H. Effect of directly welded stringer-to-beam connections on the analysis and design of modular steel building floors. Adv. Struct. Eng. 2009, 12, 373-383. [CrossRef]

27. Khan, K.; Yan, J.B. Finite Element Analysis on Seismic Behaviour of Novel Joint in Prefabricated Modular Steel Building. Int. J. Steel Struct. 2020, 20, 752-765. [CrossRef]

28. Simulia Abaqus/CAE 6.14 User's Manual; Simulia: Johnston, RI, USA, 2014; pp. 1-1146.

29. Rahiminia, F. Effects of Joint Panel Shear Deformation on Elasto-Plastic Behavior of Steel Beam-to-Column Connections; Kobe University: Kobe, Japan, 2013.

30. Śledziewski, K.; Górecki, M. Finite element analysis of the stability of a sinusoidal web in steel and composite steel-concrete girders. Materials 2020, 13, 41. [CrossRef] [PubMed]

31. Standards Australia, AS 4100-1998 (R2016) Steel structures; SAI Global Limited: Sydney, Australia, 1998.

32. Design of Structural Connections to Eurocode 3; Bulding Research Establishment, Ltd.: Hertfordshire, UK, 2003 ; ISBN 8001028380.

33. Taranath, B. Seismic Provisions for Structural Steel Buildings, ANSI/AISC 341-10. Struct. Anal. Des. Tall Build. 2011, 355-410. [CrossRef]

34. Lee, J.; Goldsworthy, H.M.; Gad, E.F. Blind bolted moment connection to sides of hollow section columns. J. Constr. Steel Res. 2011, 67, 1900-1911. [CrossRef]

35. Steel Tube Institute. Connecting Hollow Structural Section Members with Through-Bolts. Available online: https: / / steeltubeinstitute.org/resources/ connecting-hollow-structural-section-members-bolts/2020 (accessed on 29 September 2021).

36. Baniotopoulos, C.C.; Ivanyi, M. Semi-Rigid Joints in Structural Steelwork; Ivanyi, M., Baniotopoulos, C.C., Eds.; Springer: Vienna, Austria, 2000; ISBN 978-3-211-83331-5. 